\title{
Quinalizarin exerts an anti-tumour effect on lung cancer A549 cells by modulating the Akt, MAPK, STAT3 and p53 signalling pathways
}

\author{
LING-QI MENG $^{1 *}$, CHANG LIU $^{1 *}$, YING-HUA LUO ${ }^{2 *}$, XIAN-JI PIAO ${ }^{3 *}$, YUE WANG $^{1}$, YI ZHANG ${ }^{1}$, JIA-RU WANG $^{1}$, \\ HAO WANG ${ }^{1}$, WAN-TING XU ${ }^{1}$, YANG LIU ${ }^{1}$, YI-QIN WU ${ }^{1}$, HU-NAN SUN ${ }^{1}$, YING-HAO HAN ${ }^{1}$, MEI-HUA JIN ${ }^{1}$, \\ GUI-NAN SHEN ${ }^{1}$, YAN-QING ZANG ${ }^{4}$, JING LI ${ }^{1}$, NAN-ZHU FANG ${ }^{5}$, YU-DONG CUI ${ }^{1}$ and CHENG-HAO JIN ${ }^{1}$ \\ ${ }^{1}$ Department of Biochemistry and Molecular Biology, College of Life Science and Technology; ${ }^{2}$ College of Animal Science \\ and Veterinary Medicine, Heilongjiang Bayi Agricultural University, Daqing, Heilongjiang 163319; ${ }^{3}$ Department of \\ Gynaecology and Obstetrics, The Fifth Affiliated Hospital of Harbin Medical University, Daqing, Heilongjiang 163316; \\ ${ }^{4}$ College of Food Science and Technology, Heilongjiang Bayi Agricultural University, Daqing, Heilongjiang 163319; \\ ${ }^{5}$ Department of Animal Science, College of Agriculture, Yanbian University, Yanji, Jilin 133002, P.R. China
}

Received June 20, 2017; Accepted November 9, 2017

DOI: $10.3892 / \mathrm{mmr} .2017 .8110$

\begin{abstract}
Quinalizarin may be a potential chemical agent for cancer therapy, as it exerts anti-tumour effects against a variety of different types of cancer. However, the underlying regulatory mechanism and signalling pathways of quinalizarin in lung cancer cells remains unknown. The present study sought to investigate the effects of quinalizarin on proliferation, apoptosis and reactive oxygen species (ROS) generation in lung cancer. MTT assays were used to evaluate the effects of quinalizarin on the viability of lung cancer A549, NCI-H460 and NCI-H23 cells. Flow cytometry was employed to evaluate the effects of quinalizarin on the cell cycle, apoptosis and ROS generation in A549 cells. Western blotting was performed to detect cell cycle and apoptosis-associated protein expression levels in A549 cells. Quinalizarin inhibited A549, NCI-H460 and NCI-H23 cell proliferation and induced A549 cell cycle arrest at the $G_{0} / G_{1}$ phase. Quinalizarin induced apoptosis by upregulating the expression of B-cell lymphoma 2 (Bcl-2)-associated agonist of cell death, cleaved-caspase-3 and cleaved-poly (adenosine diphosphate-ribose) polymerase, and
\end{abstract}

Correspondence to: Professor Cheng-Hao Jin or Professor Yu-Dong Cui, Department of Biochemistry and Molecular Biology, College of Life Science and Technology, Heilongjiang Bayi Agricultural University, 5 Xinfa Street, Daqing, Heilongjiang 163319, P.R. China

E-mail: jinchenghao3727@qq.com

E-mail: 1016856109@qq.com

${ }^{*}$ Contributed equally

Key words: quinalizarin, lung cancer cells, cell cycle arrest, cell apoptosis, reactive oxygen species, protein kinase B, mitogen-activated protein kinase, signal transducer and activator of transcription-3 downregulating the expression of Bcl-2. Furthermore, quinalizarin activated mitogen-activated protein kinase (MAPK) and p53, and inhibited the protein kinase B and signal transducer and activator of transcription-3 (STAT3) signalling pathways. In addition, quinalizarin increased ROS generation. The ROS scavenger N-acetyl-L-cysteine restored quinalizarin-induced cell apoptosis, and inactivated the MAPK and STAT3 signalling pathways. The results of the present study demonstrated that quinalizarin induces $\mathrm{G}_{0} / \mathrm{G}_{1}$ phase cell cycle arrest and apoptosis via ROS mediated-MAPK and STAT3 signalling pathways.

\section{Introduction}

Among cancers, lung cancer has the highest incidence and cancer-associated mortality worldwide (1-3). In 2015, nearly 733,300 new lung cancer cases and 610,200 lung cancer deaths occurred in China (4). Despite improvements in early detection and therapeutic strategies, the prognosis with standard treatments for patients remains poor, with a 5-year relapse rate of $80 \%$ (5). Many investigations have sought to identify novel drug targets and effective ways to combat lung cancer, however, significant research is still required (6-8). Therefore, there is an urgency to develop novel effective agents to treat lung cancer.

The Akt signalling pathway is involved in cellular proliferation, survival and apoptosis in various types of cancer and has been recognized as a potential molecular target for cancer therapy (9-11). Activated Akt has been shown to promote tumour progression in various cancers through cell cycle arrest and the promotion of apoptosis (11). Abundant evidences indicated that anti-cancer agents regulate biological behaviour via Akt in various cancer cell lines. The activity of Akt is also regulated by casein kinase 2 (CK2) inhibitor (12). Mitogen-activated protein kinase (MAPK) signalling pathways relay and integrate signals from a wide range of stimuli and control cellular proliferation, cell cycle and apoptosis (13-17). 
Therefore, the MAPK in these signalling pathways are considered 'stress-activated protein kinases' in cellular signalling, inflammation, apoptosis and the pathogenesis of various diseases. The signal transducer and activator of transcription-3 (STAT3) signalling pathway has been shown to regulate the transcriptional activation of gene products that participate in cell proliferation and anti-apoptosis, such as cell cycle (cyclins and cyclin-dependent kinases, Cdks) and apoptotic regulators (Bcl-2 and Bad) (18). These findings indicate that the targeting of Akt, MAPK and STAT3 signalling pathways may be an important therapeutic target in novel cancer therapy.

Reactive oxygen species (ROS) are one of the major causes of tumours and have significant roles in the processes of tumour progression, metastasis and apoptosis (19-21). Intracellular levels of ROS play key roles in survival and various physiological functions and also proven to be able to promote cell proliferation and apoptosis through threshold levels (22). Many studies have shown that ROS accumulation directly increases mitochondrial dysfunction and the subsequent initiation of apoptosis (22-24). Furthermore, ROS or oxidative stress-responses may alter various cancer developments by activating canonical ROS-responsive signalling pathways such as MAPK and STAT3 pathways (24). Thus, increasing intracellular ROS generation and modulating the MAPK and STAT3 signalling pathways may be an effective approach in the treatment and prevention of cancers.

Casein kinase 2 (CK2) has been shown to be involved in malignant proliferation, apoptosis resistance and signal transduction in different cancer cells (25-27). Many studies have confirmed the underlying targeting of protein kinase CK2 inhibitors for various cancer therapies (25-28). Quinalizarin is a protein kinase $\mathrm{CK} 2$ and ATP-competitive inhibitor that has previously been shown to be a potent, highly selective and cell-permeable inhibitor (28). Quinalizarin has been reported to promote apoptosis in human nasopharyngeal carcinoma CNE-1 and CNE-2 cells (29). However, the underlying molecular mechanisms of quinalizarin-induced apoptosis in lung cancer cells remain unknown.

In the present study, we examined the effect of quinalizarin on anti-proliferation, inducing cell cycle arrest, apoptosis and ROS generation in lung cancer cell lines. The roles of the Akt, MAPK, STAT3 and p53 signalling pathways in quinalizarin-induced cell apoptosis and intracellular ROS generation were examined.

\section{Materials and methods}

Cell culture. Lung cancer A549, NCI-H460, NCI-H23 cell lines and normal liver QSG-7701 cell lines were obtained from American Type Culture Collection (Manassas, VA, USA). Cells were cultured in DMEM (Gibco; Thermo Fisher Scientific, Inc., Waltham, MA, USA), supplemented with $10 \%$ foetal bovine serum (FBS), penicillin $(100 \mathrm{U} / \mathrm{ml})$ and streptomycin $\left(100 \mu \mathrm{g} / \mathrm{ml}\right.$; Gibco) in a $5 \% \mathrm{CO}_{2}$ humidified atmosphere at $37^{\circ} \mathrm{C}$. Cells were monitored daily, and medium was replaced every 2 days at $70 \%$ cell density.

Cell cytotoxicity assays. A549, NCI-H460, NCI-H23 and QSG-7701 cells were harvested at logarithmic phase and dispensed into 96-well plates at a density of 5,000 cells per well. After $24 \mathrm{~h}$ of incubation, the A549, NCI-H460, NCI-H23 and QSG-7701 cells were treated with various concentrations $(1,3,10,30$ and $100 \mu \mathrm{mol} / \mathrm{l})$ of 5-fluorouracil (5-FU) and quinalizarin (Sigma-Aldrich, St. Louis, MO, USA) for $24 \mathrm{~h}$. Controls included untreated and dimethyl sulfoxide (DMSO; Sigma-Aldrich) treated cells. MTT solution $(20 \mu \mathrm{l} ; 5 \mathrm{mg} / \mathrm{ml})$ was added to the wells, and $2 \mathrm{~h}$ later, the intracellular formazan crystals that had formed were solubilized with $100 \mu 1 \mathrm{DMSO}$, and the cells were incubated for an additional $15 \mathrm{~min}$ at $37^{\circ} \mathrm{C}$. The absorbance values of the solution were measured at $540 \mathrm{~nm}$ with a microplate luminometer. Percentage viability was calculated as (OD of drug-treated sample/OD of control sample) x100.

Cell cycle analysis. A549 cells in logarithmic phase were seeded onto 6 -well culture plates $\left(1 \times 10^{5}\right.$ cells/well $)$ and cultured $24 \mathrm{~h}$. Then, the cells were treated with $12.1 \mu \mathrm{mol} / 1$ quinalizarin for $0,3,6,12$ and $24 \mathrm{~h}$. Cells were trypsinized and fixed in $70 \%$ ethanol at $4^{\circ} \mathrm{C}$ for $12 \mathrm{~h}$ and washed with PBS 2-3 times. Cells were resuspended in $195 \mu \mathrm{l}$ binding buffer and incubated with RNase and propidium iodide (PI; Beyotime Biotechnology, Shanghai, China) for $30 \mathrm{~min}$ without bright light at $37^{\circ} \mathrm{C}$. The cellular DNA content of the treated cells was analysed by flow cytometry (BD Biosciences, San Jose, CA, USA) with a $488 \mathrm{~nm}$ argon laser.

Cell apoptosis analysis. Early and late apoptosis was analysed by Annexin V-FITC/PI double staining and flow cytometry. Cells in the logarithmic growth phase were plated onto 6-well plates at a density of $1 \times 10^{5}$ cells/well and incubated overnight. After being treated with quinalizarin $(12.1 \mu \mathrm{mol} / \mathrm{l})$ for $0,3,6$, 12 and $24 \mathrm{~h}$, cells were centrifuged at 5,000 x g for $7 \mathrm{~min}$ at $4^{\circ} \mathrm{C}$ and washed with PBS 2-3 times. Each sample was stained with $5 \mu \mathrm{l}$ Annexin V-FITC and $3 \mu \mathrm{l}$ PI at room temperature for $20 \mathrm{~min}$ in the absence of bright light, and cells were then detected by flow cytometry. The results are reported as the mean values from three independent experiments.

Western blotting analysis. Cells were washed in PBS and lysed in cell extraction buffer (1 M HEPES, pH 7.0; $5 \mathrm{M} \mathrm{NaCl}$; $0.5 \%$ Triton X-100; $10 \%$ glycerol; 20 mM $\beta$-mercaptoethanol; $20 \mathrm{mg} / \mathrm{ml} \mathrm{AEBSF} ; 0.5 \mathrm{mg} / \mathrm{ml}$ pepstatin; $0.5 \mathrm{mg} / \mathrm{ml}$ leupeptin; and $2 \mathrm{mg} / \mathrm{ml}$ aprotinin). Cell lysates were centrifuged for $30 \mathrm{~min}$ at $12,000 \mathrm{xg}$ and $4^{\circ} \mathrm{C}$. Then, the supernatants were dissolved with $5 \mathrm{x}$ sample loading buffer and boiled for $5 \mathrm{~min}$. The resulting supernatants $(30 \mu \mathrm{g})$ were separated on $10 \%$ SDS-PAGE and transferred to NC membranes. The membranes were blocked with $5 \%$ skim milk for $2 \mathrm{~h}$ at room temperature and incubated for $12 \mathrm{~h}$ (overnight) at $4{ }^{\circ} \mathrm{C}$ with the following primary antibodies (all obtained from Santa Cruz Biotechnology, Inc., Dallas, TX, USA): Mouse monoclonal antibodies against $\beta$-actin (1:2,500; cat.no. sc-47778), $\alpha$-tubulin (1:2,500; cat. no. sc-8035), Bad (1:1,500; cat. no. sc-8044), Bcl-2 (1:1,500; cat. no. sc-7382), PARP-1 (1:1,500; cat. no. sc-8007), cleaved caspase-3 (cle-caspase-3; 1:1,500; cat. no. sc-373730), p-ERK (1:1,500; cat. no. sc-7383), p-JNK (1:1,500; cat.no. sc-6254), JNK (1:1,500; cat. no. sc-7345), p-p38 (1:1,500; cat. no. sc-7973), p-STAT3 (1:1,500; cat. no. sc-8059), STAT3 (1:1,500; cat. no. sc-8019); and rabbit polyclonal antibodies against CDK2 (1:2,500; cat. no. sc-163), CDK4 (1:2,500; 
cat. no. sc-260), CDK6 (1:2,500; cat. no. sc-177), cyclin D1 (1:2,500; cat. no. sc-753), cyclin E (1:2,500; cat. no. sc-481), p21 (1:1,500; cat. no. sc-397), p27 (1:2,500; cat. no. sc-528), pro caspase-3 (1:2,500; cat. no. sc-7148), ERK2 (1:1,500; cat. no. sc-154), p38 $\alpha / \beta$ (1:1,500; cat. no. sc-7194), p-p53 (1:2,500; cat. no. sc-101762), p53 (1:1,500; cat. no. sc-6243), Akt1/2/3 (1:1,500; cat. no. sc-8312), and p-Akt1/2/3 (1:2,500; cat. no. sc-7985-R). Peroxidase-Conjugated Affini Pure Goat Anti-Mouse IgG (1:5,000; cat. no. ZB-2305) and Goat Anti-Rabbit IgG (1:5,000; cat. no. ZB-2301) were used as the secondary antibodies. Membranes were incubated with chemiluminescence reagent (Millipore, Billerica, MA, USA), detected by a chemiluminescence instrument and analysed by using ImageJ $1.42 q$ software.

Detection of ROS. The generation of intracellular ROS in response to quinalizarin treatment in A549 cells was measured by using 2',7'-dichlorofluorescein diacetate (DCFH-DA; MERCK, Shanghai, China) permeates. Cells were plated onto 6 -well culture plates $\left(1 \times 10^{5}\right.$ cells/well) and incubated for $24 \mathrm{~h}$. Then, the cells were treated with quinalizarin $(12.1 \mu \mathrm{mol} / \mathrm{l})$ for $0,3,6,12$ and $24 \mathrm{~h}$, harvested at 5,000 x $\mathrm{g}$ for $5 \mathrm{~min}$ and incubated with DCFH-DA for $30 \mathrm{~min}$ in the dark. The results were analysed by flow cytometry (Beckman Coulter, Inc., Brea, CA, USA).

Statistical analysis. Data were presented as the mean \pm standard deviation and all of the experiments were replicated 3 times. Statistical analyses were performed using Excel. One-way analysis of variance or Student's t-test was used to evaluate the statistical significance between controls with treated groups. $\mathrm{P}<0.05$ indicated statistically significant differences.

\section{Results}

Quinalizarin has cytotoxic effects on lung cancer cells. To determine whether quinalizarin had cytotoxic effects in lung cancer cells (A549, NCI-H23 and NCI-H460), cell viabilities were detected with MTT assays. As shown in Fig. 1A-C, quinalizarin inhibited the cell viability of the three lung cancer cell types (A549, NCI-H23 and NCI-H460) in a concentration-dependent manner. Furthermore, there were significant differences after quinalizarin treatment compared with 5-FU treatment. The inhibition rate of quinalizarin on A549 cells $\left(\mathrm{IC}_{50}, 12.1 \mu \mathrm{mol} / \mathrm{l}\right)$ was higher than those on NCI-H23 $\left(\mathrm{IC}_{50}, 20.24 \mu \mathrm{mol} / \mathrm{l}\right)$ and NCI-H460 ( $\left.\mathrm{IC}_{50}, 27.94 \mu \mathrm{mol} / \mathrm{l}\right)$ cells at $24 \mathrm{~h}$. Furthermore, there were no significant cytotoxic effects of quinalizarin compared with 5-FU treatments in normal liver QSG-7701 cells (Fig. 1D). These results indicated that quinalizarin has significant dose-dependent cell toxicity effects in lung cancer cells. Because A549 cells were more sensitive to quinalizarin, we used A549 cells as a representative for subsequent experiments.

Quinalizarin induces cell cycle arrest and regulates expression of cell cycle-related proteins in A549 cells. To investigate whether quinalizarin induced growth inhibition and cell cycle arrest, cells exposed to quinalizarin were analysed with flow cytometry and western blotting. As shown in Fig. 2A and B, the percentage of cells in $G_{0} / G_{1}$ phase was significantly increased compared with the control groups, and cell numbers in $\mathrm{G}_{2} / \mathrm{M}$ phase decreased. These results suggested that quinalizarin induced cell cycle arrest at $\mathrm{G}_{0} / \mathrm{G}_{1}$ phase in a time-dependent manner. To further investigate whether the CDK/cyclin signalling pathway was involved in quinalizarin-induced cell cycle arrest, $\mathrm{G}_{0} / \mathrm{G}_{1}$ phase regulatory proteins were examined. A549 cellular protein expression levels of CDK2/4/6 and cyclin $\mathrm{D} 1 / \mathrm{E}$ were repressed, and p21 and p27 were increased in a time-dependent manner (Fig. 2C and D). These results showed that quinalizarin induces A549 cell cycle arrest at $G_{0} / G_{1}$ phase in a time-dependent manner, with decreased expression levels of CDK2/4/6 and cyclin D1/E.

Quinalizarin induces apoptosis in A549 cells. To investigate whether quinalizarin induced apoptosis in lung cancer cells, A549 cells were treated with quinalizarin for different time (0, 3, 6, 12 and $24 \mathrm{~h})$, and apoptosis was observed by Annexin V-FITC/PI double staining. Fluorescence intensity and morphology changes were observed by fluorescence microscope. The fluorescence intensity of Annexin V-FITC and PI of quinalizarin-treatment cells was increased in a time-dependent manner (Fig. 3A and B). Especially after $24 \mathrm{~h}$ of treatment with quinalizarin, apoptosis was most apparent as compared with that in the bright field groups. Cells had decreased in size and were rounded and floating, thus further demonstrating the ability of quinalizarin to induce apoptosis in lung cancer cells. The percentage of early and late apoptosis was quantified by flow cytometry (Fig. 3C and D). The percentages of apoptotic cells increased from 5.87 to $64.57 \%$ for the A549 cells, thus suggesting that quinalizarin is a potent inducer of apoptosis in A549 cells.

Quinalizarin induces apoptosis in A549 cells via alterations in Bcl-2 family proteins and caspase activation. To investigate whether quinalizarin induced apoptosis via the mitochondrial pathway, we detected apoptotic protein expression levels by western blotting. As shown in Fig. 4A and B, quinalizarin significantly increased the protein expression level of $\mathrm{Bad}$ and decreased that of Bcl-2. Furthermore, quinalizarin increased caspase- 3 and PARP activity in a time-dependent manner. These results indicated that the induction of apoptosis was associated with the down-regulation of Bcl-2 and the up-regulation of Bad, cle-caspase-3 and cleaved PARP in lung cancer cells. These results showed that quinalizarin induces apoptosis via the activation of common apoptotic regulators.

Quinalizarin activates Akt, MAPKs, STAT3 and p53 signalling pathways. To investigate the mechanism underlying quinalizarin-induced apoptosis in A549 cells, Akt, MAPK, STAT3 and p53 signalling pathway-related proteins were analysed by western blotting. As shown in Fig. 5A-F, the phosphorylation of Akt, ERK and STAT3 was significantly decreased and the phosphorylation of JNK, p38 and p53 was significantly increased after quinalizarin treatment. These results suggested that quinalizarin-induced activation of the Akt, MAPK, STAT3 and p53 signalling pathways promote A549 cell apoptosis.

Quinalizarin induces intracellular ROS generation and ROS scavenger NAC suppression of cell apoptosis. To investigate the relationship between ROS generation and cell 


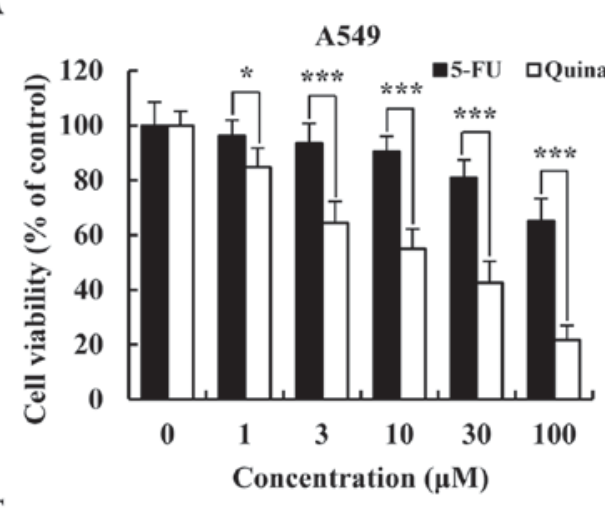

C

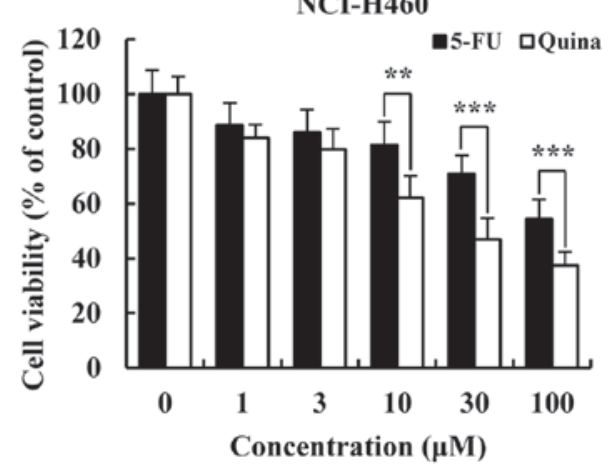

B

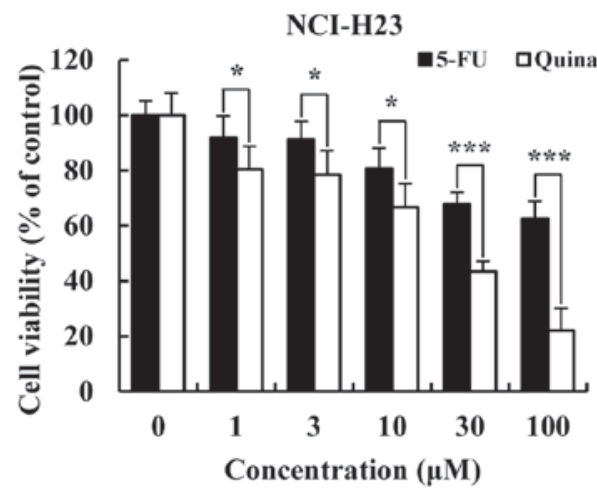

D

QSG-7701

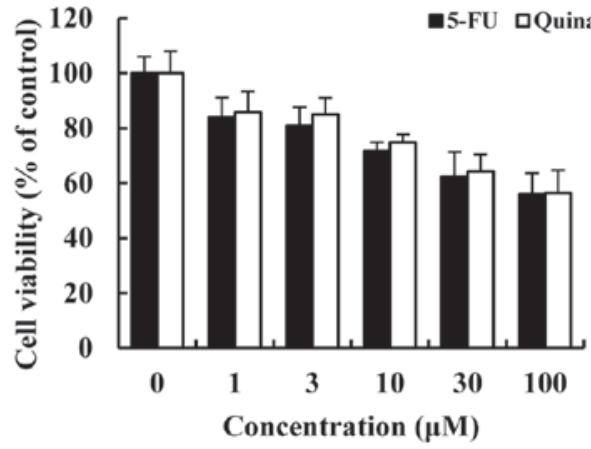

Figure 1. Cytotoxic effects of quinalizarin on lung cancer cells. Cell viabilities were expressed as a percentage of viable cells compared with control cells. Effects of 5-FU and quinalizarin on (A) A549, (B) NCI-H23, (C) NCI-H460 and (D) QSG-7701 cell viability. Data are presented as the mean \pm standard deviation. ${ }^{*} \mathrm{P}<0.05,{ }^{* *} \mathrm{P}<0.01$ and ${ }^{* * * *} \mathrm{P}<0.001$ vs. 5-FU group. 5-FU, 5 -fluorouracil; Quina, quinalizarin.

A

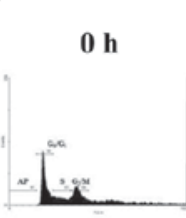

$3 \mathbf{h}$

C
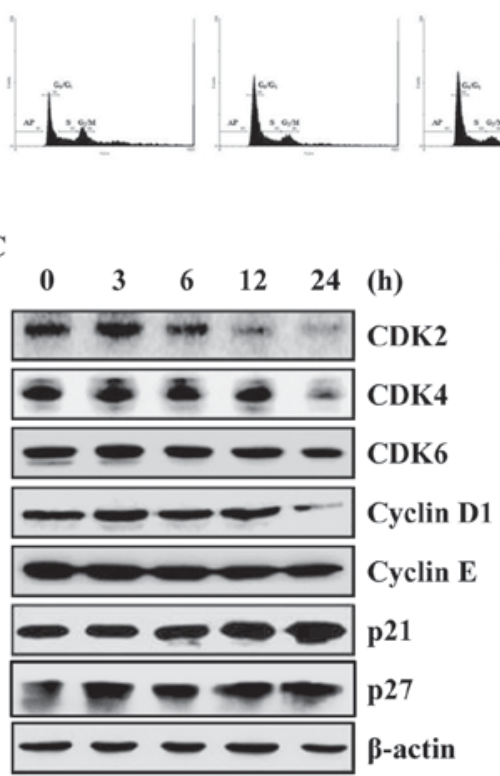

$6 \mathrm{~h}$

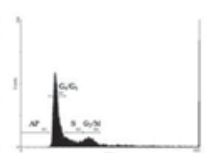

D

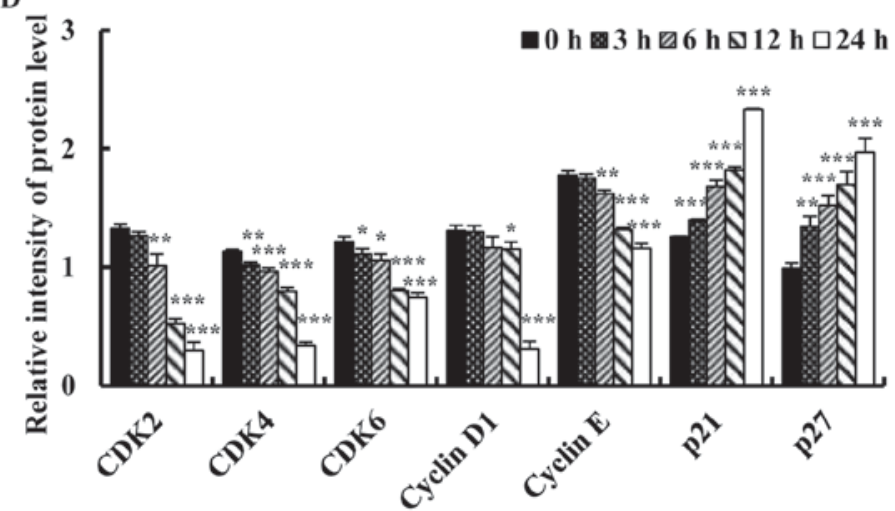

Figure 2. Quinalizarin induced A549 cell cycle arrest at $G_{0} / G_{1}$ phase and affected the cell cycle regulatory proteins in A549 lung cancer cells. (A) Cells were treated with $12.1 \mu \mathrm{mol} / 1$ quinalizarin at $0,3,6,12$ and $24 \mathrm{~h}$, and the cell cycle distribution was analysed by flow cytometry, and (B) quantified. (C) Cells were treated with $12.1 \mu \mathrm{mol} / 1$ quinalizarin for the indicated times ( 0 to $24 \mathrm{~h}$ ), and were then subjected to western blotting to detect the expression of the cell cycle associated proteins CDK2/4/6, cyclin D1/E, p21 and p27. (D) Quantification of western blot analysis. Data are presented as the mean \pm standard deviation. ${ }^{*} \mathrm{P}<0.05,{ }^{* *} \mathrm{P}<0.01$ and ${ }^{* * * *} \mathrm{P}<0.001$ vs. control group $(0 \mathrm{~h})$. CDK, cyclin dependent kinase.

apoptosis, quinalizarin-treated A549 cells were used to study the mechanism of ROS generation during apoptosis. As shown in Fig. 6A and B, ROS levels increased under quinalizarin treatment in a time-dependent manner. After incubation with quinalizarin and N-acetyl-L-cysteine (NAC), ROS levels were significantly decreased as compared with the levels in the 
A

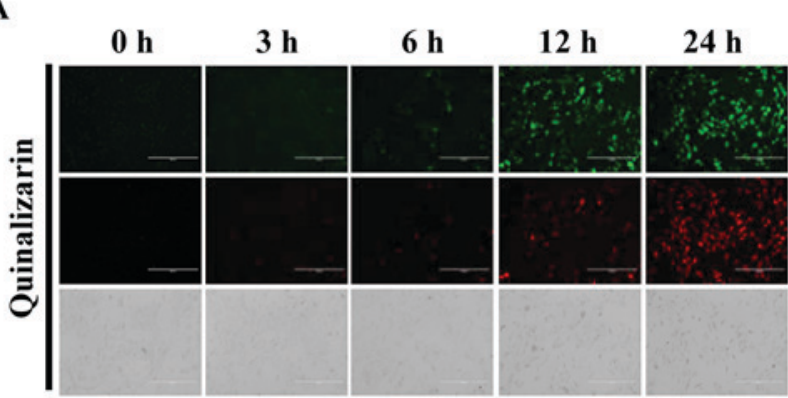

C

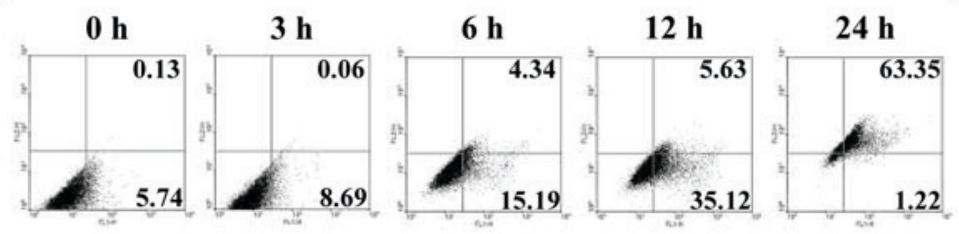

B Annexin V

PI

Bright field

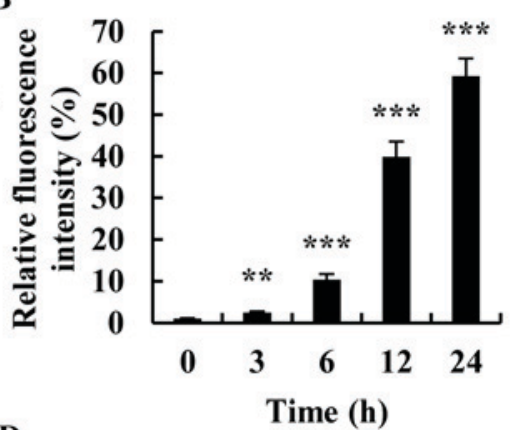

D

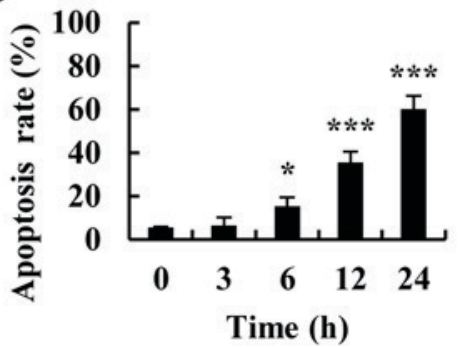

Figure 3. Morphological changes and fluorescence intensity of A549 cells treated with quinalizarin. (A) Quinalizarin at a concentration of $12.1 \mu \mathrm{mol} / 1 \mathrm{was}$ added to the cells and incubated for the indicated times ( 0 to $24 \mathrm{~h}$ ), and cellular morphology and fluorescence intensity were then observed by fluorescence microscopy. Scale bar=200 $\mu \mathrm{m}$. (B) Quantification of fluorescence intensity. (C) Quinalizarin at a concentration of $12.1 \mu \mathrm{mol} / 1$ was incubated with cells for the indicated times ( 0 to $24 \mathrm{~h}$ ), and apoptosis distribution was analysed by flow cytometry and then (D) quantified. Data are presented as the mean \pm standard deviation. ${ }^{*} \mathrm{P}<0.05,{ }^{* *} \mathrm{P}<0.01$ and ${ }^{* * * *} \mathrm{P}<0.001$ vs. control group $(0$ h). PI, propidium iodide.

A

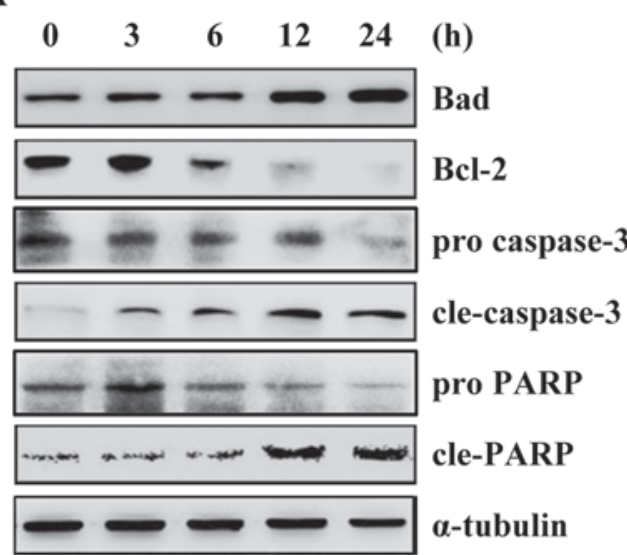

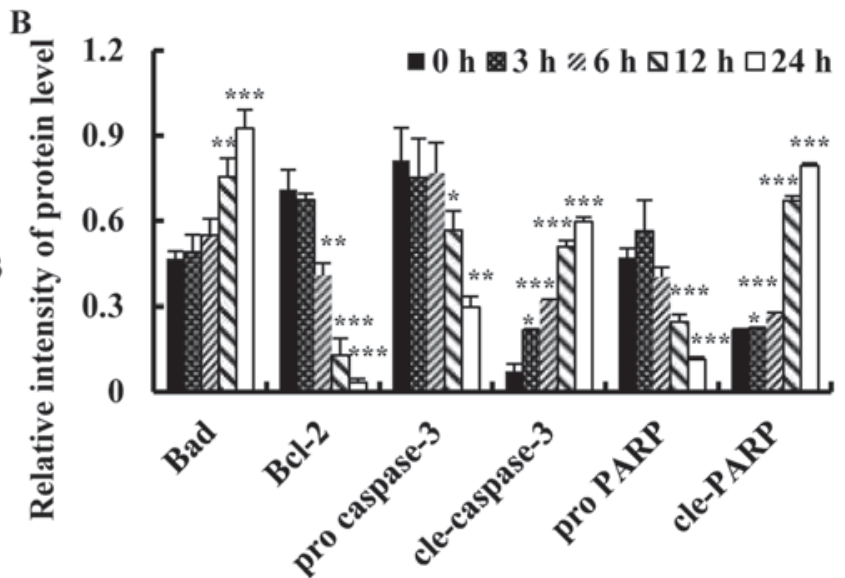

Figure 4. Apoptotic effects of quinalizarin in A549 cells. (A) Effects of quinalizarin on the expression levels of Bad, Bcl-2, cleaved capase-3 and cleaved PARP in A549 lung cancer cells were analysed by western blotting and (B) quantification. ${ }^{*} \mathrm{P}<0.05,{ }^{* *} \mathrm{P}<0.01,{ }^{* * * *} \mathrm{P}<0.001$ vs. control group (0 h). Bcl-2, B-cell lymphoma 2; Bad, Bcl-2-associated agonist of cell death; PARP, poly (adenosine diphosphate-ribose) polymerase; cle, cleaved.

quinalizarin group (Fig. 6C and D). Scavenging of ROS also significantly decreased quinalizarin-induced cell apoptosis (Fig. 6E and F). Next, we used Western blotting to confirm the anti-apoptotic mechanism of ROS in quinalizarin-induced cell apoptosis. After incubation with quinalizarin and NAC, the phosphorylation of ERK and STAT3 increased and p38, JNK, cle-caspase-3 and cle-PARP were decreased (Fig. 7A and B). These data indicated that quinalizarin induces cell apoptosis through the generation of ROS via the MAPK and STAT3 signalling pathways. SB203580 (p38 inhibitor), SP600125 (JNK inhibitor) and FR180204 (ERK inhibitor) were applied to confirm the role of MAPK and STAT3 signalling pathways in the quinalizarin-induced apoptosis on lung cancer cells. A549 cells were pre-treated with $12.1 \mu \mathrm{mol} / 1$ of SB203580,
SP600125 or FR180204 for $30 \mathrm{~min}$ followed by treatment with quinalizarin for $24 \mathrm{~h}$. The decreased protein expression levels of p-STAT3 induced by quinalizarin were suppressed by adding the p38MAPK inhibitor and JNK inhibitor, enhanced by adding the ERK inhibitor (Fig. 8A-F). These results showed that MAPK was involved in regulating the STAT3 signalling pathway and induced apoptosis in lung cancer A549 cell.

\section{Discussion}

Potential growth inhibition and apoptosis-inducing effects of quinalizarin on lung cancer cell lines were explored. Cell proliferation follows the progression of the cell cycle. In eukaryotes, mitosis is dependent on the completion of 
A
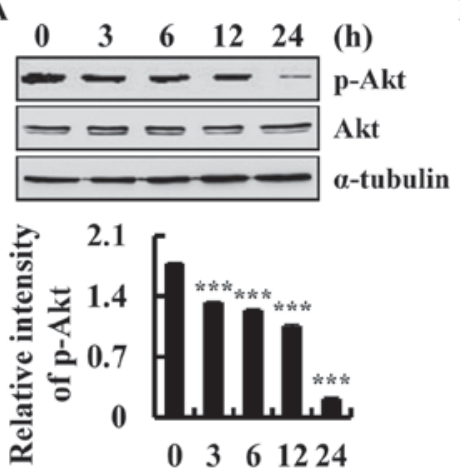

Time (h)
B
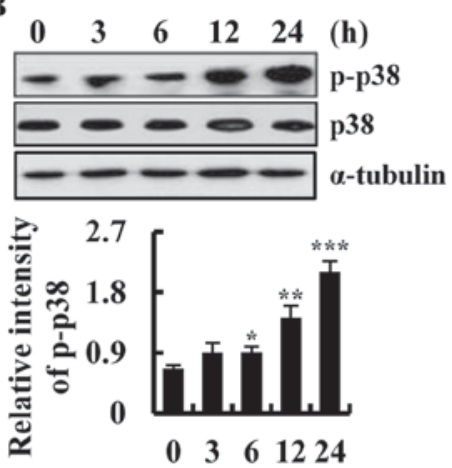

Time (h)
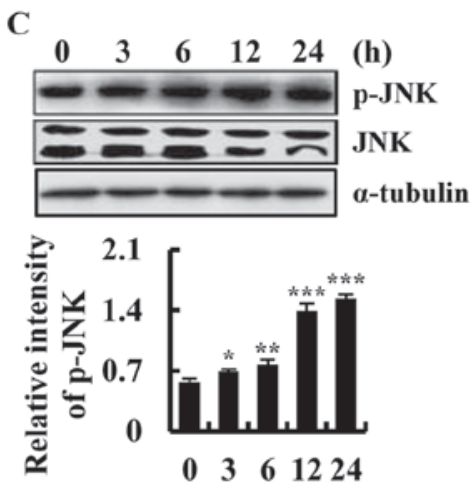

Time (h)

D

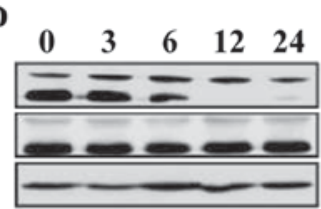

(h)

E p-ERK ERK

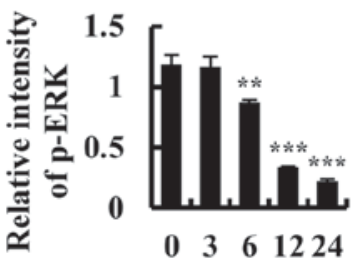

Time (h)
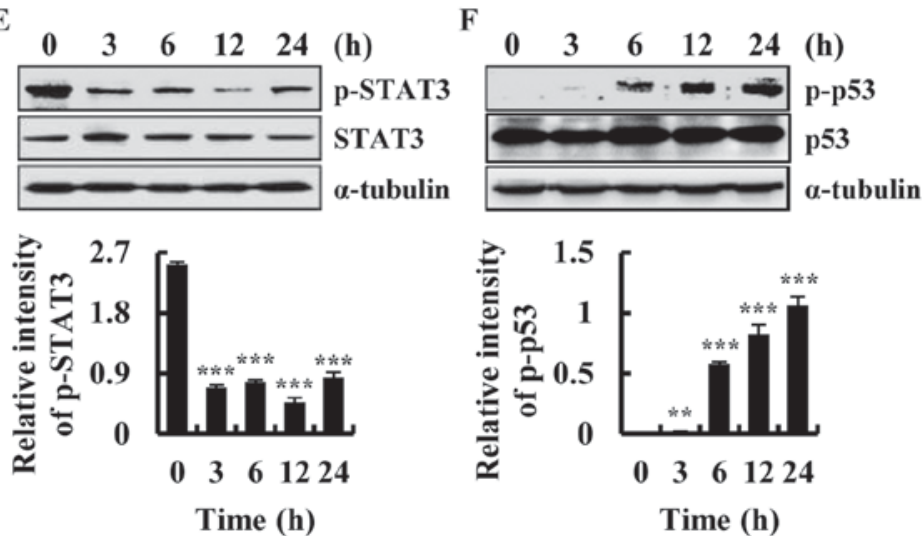

Figure 5. Quinalizarin induces apoptosis via Akt, mitogen-activated protein kinases, STAT3 and p53 signalling pathways. The expression of (A) Akt, (B) p38, (C) JNK, (D) ERK, (E) STAT3 and (F) p53 proteins was detected by western blot analysis. ${ }^{*} \mathrm{P}<0.05,{ }^{* *} \mathrm{P}<0.01$ and ${ }^{* * * *} \mathrm{P}<0.001$ vs. control group (0 h). Akt, protein kinase B; JNK, c-Jun N-terminal kinase; ERK, extracellular signal-regulated kinases; STAT3, signal transducer and activator of transcription-3; p-, phosphorylated.

A

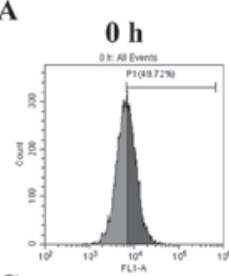

C

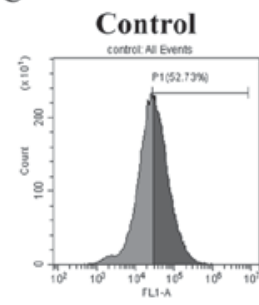

E

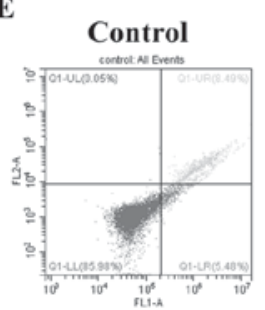

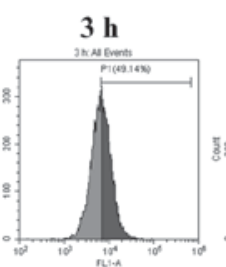

NAC

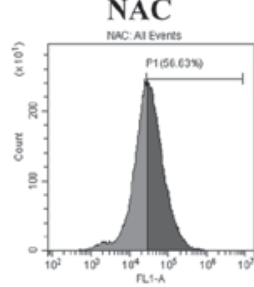

NAC

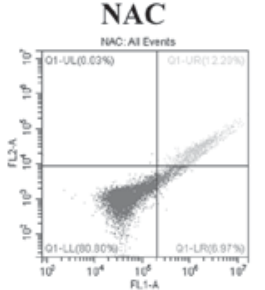

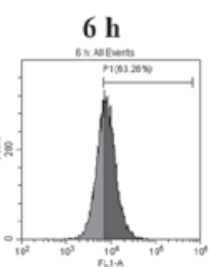
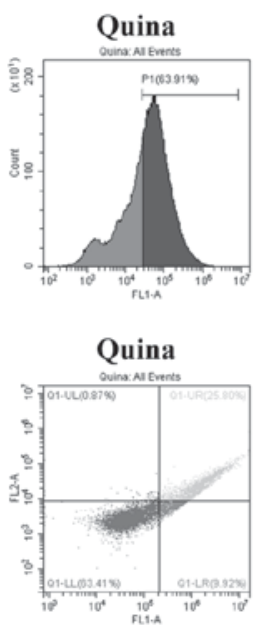

$12 \mathrm{~h}$
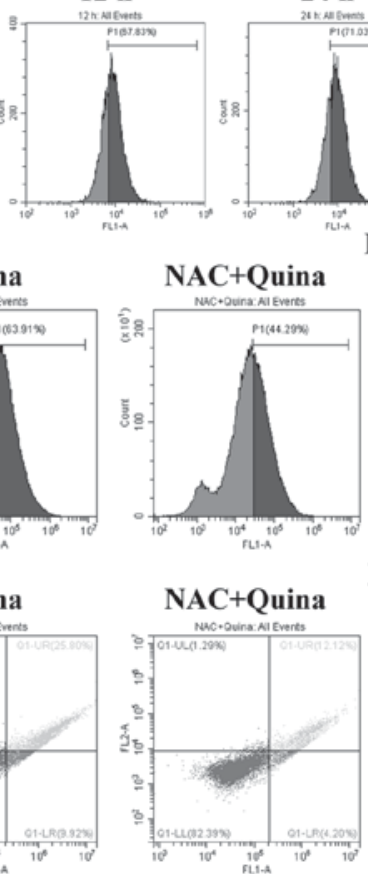

B
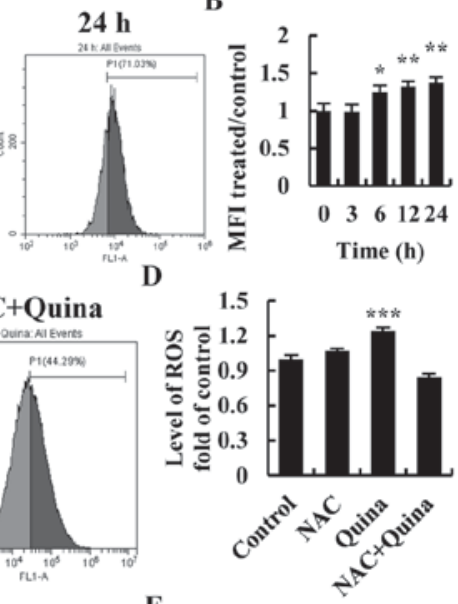

F

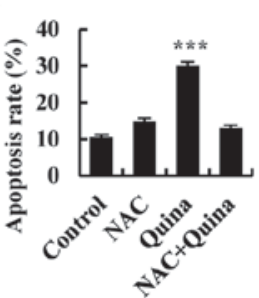

Figure 6. Quinalizarin induces ROS-mediated apoptosis in A549 cells. (A) Quinalizarin at a concentration of $12.1 \mu$ mol/1 was incubated with cells for the indicated times (0 to $24 \mathrm{~h}$ ), and the intracellular ROS levels were evaluated by flow cytometry and (B) then the intracellular ROS generation quantified. (C) A549 cells were incubated with NAC or quinalizarin for $24 \mathrm{~h}$, and the generation of ROS were analysed by flow cytometry and then (D) quantified. (E) A549 cells were incubated with NAC or quinalizarin for $24 \mathrm{~h}$, and cell apoptosis was analysed by flow cytometry and then $(\mathrm{F})$ quantified. ${ }^{*} \mathrm{P}<0.05,{ }^{* *} \mathrm{P}<0.01$, ${ }^{* * *} \mathrm{P}<0.001$ vs. NAC + Quina group. ROS, reactive oxygen species; NAC, N-acetyl-L-cysteine; Quina, quinalizarin. 
A

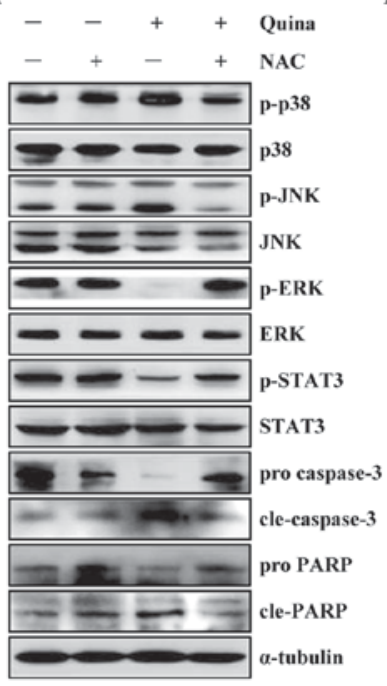

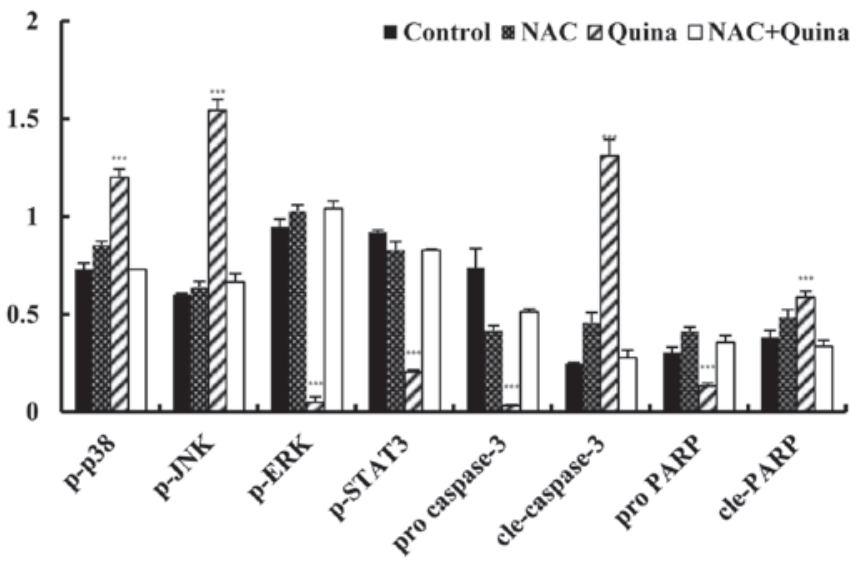

Figure 7. Quinalizarin induces ROS-mediated apoptosis via mitogen-activated protein kinase and STAT3 signalling pathways. (A) The relative protein expression levels of $\mathrm{p} 38$, JNK, ERK, STAT3, cleaved-caspase-3 and cleaved-PARP were detected by western blotting and (B) quantified. ${ }^{* * *} \mathrm{P}<0.001 \mathrm{vs.}$ NAC + Quina group. ROS, reactive oxygen species; NAC, N-acetyl-L-cysteine; Quina, quinalizarin; JNK, c-Jun N-terminal kinase; ERK, extracellular signal-regulated kinases; STAT3, signal transducer and activator of transcription-3; p-, phosphorylated; PARP, poly (adenosine diphosphate-ribose) polymerase; cle, cleaved.

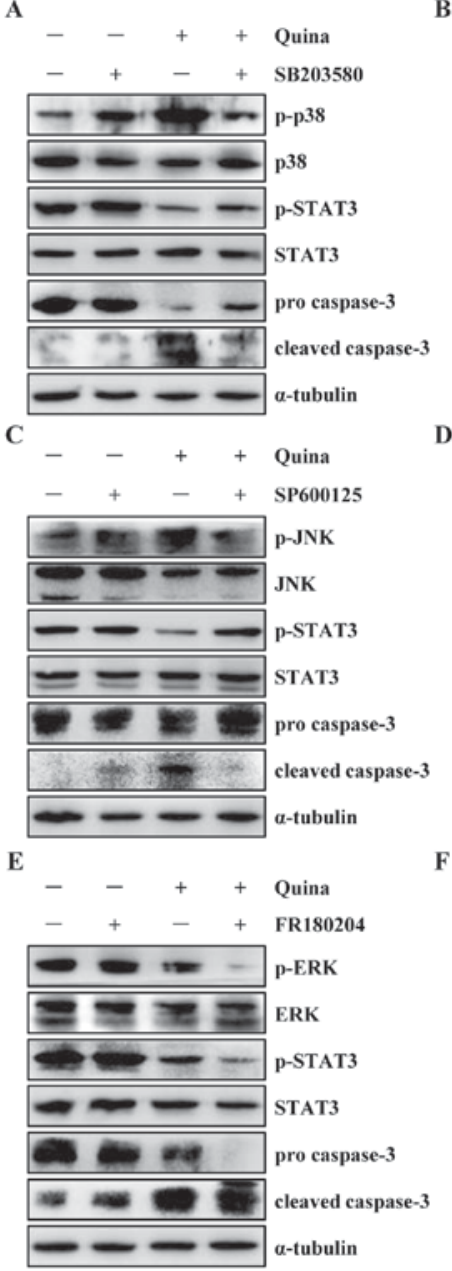

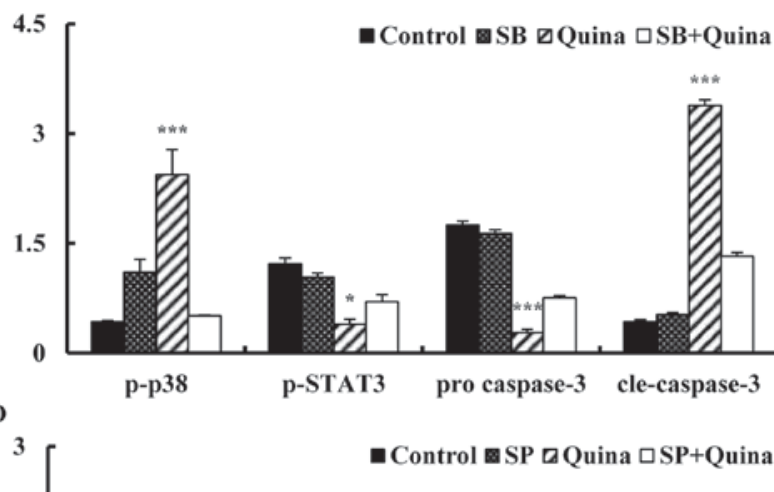
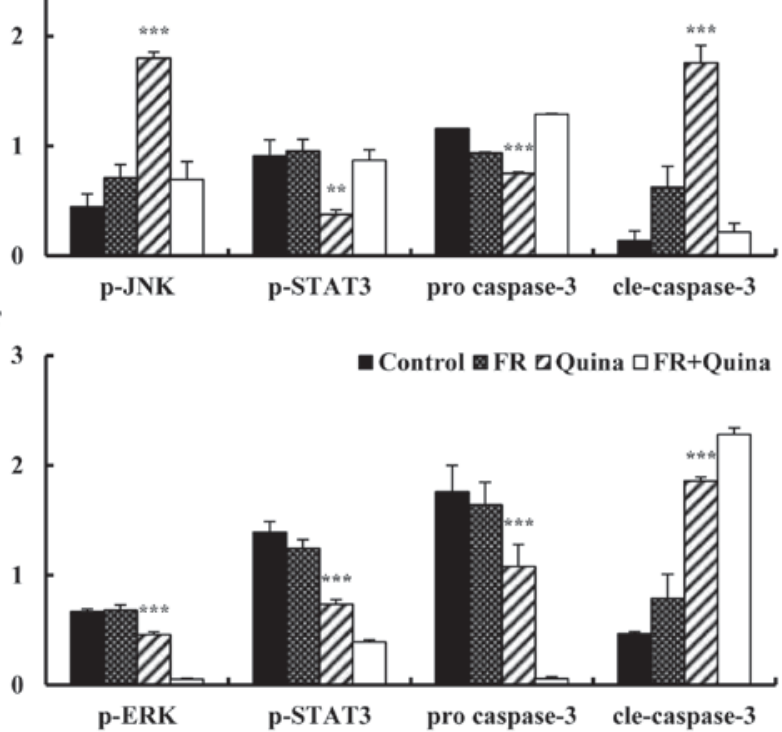

Figure 8. Effect of quinalizarin on mitogen-activated protein kinase and STAT3 signalling pathways in A549 cells. (A) Expression of p-p38, p-STAT3 and cleaved caspase-3, in quinalizarin and p38 inhibitor SB203580-treated A549 cells. (B) Relative levels of p-p38, p-STAT3 and cleaved caspase-3 were calculated using ImageJ. (C) Expressions of p-JNK, p-STAT3 and cleaved caspase-3, in the quinalizarin and JNK inhibitor SP600125-treated A549 cells. (D) Relative levels of p-JNK, p-STAT3 and cleaved caspase-3 were calculated using Image J. (E) Expressions of p-ERK, p-STAT3 and cleaved caspase-3, in the quinalizarin and ERK inhibitor FR180204-treated A549 cells. (F) Relative levels of p-ERK, p-STAT3 and cleaved caspase-3 were calculated using Image J. ${ }^{*} \mathrm{P}<0.05,{ }^{* *} \mathrm{P}<0.01$ and ${ }^{* * * *} \mathrm{P}<0.001$ vs. inhibitor + Quina group. SB, SB203580; SP, SP600125; FR, FR 180204; Quina, quinalizarin; STAT3, signal transducer and activator of transcription-3; JNK, c-Jun N-terminal kinase; ERK, extracellular signal-regulated kinases; p-, phosphorylated; cle, cleaved. 
DNA synthesis (30). Checkpoints play important roles in the regulation of the cell cycle in eukaryotic cells, and abnormal regulation of these checkpoints frequently occurs in tumour cells (31). Cells may be arrested at $\mathrm{G}_{0} / \mathrm{G}_{1}, \mathrm{~S}$ and $\mathrm{G}_{2} / \mathrm{M}$ phases of the cell cycle (32). Indeed, quinalizarin has been reported to decrease CDK1 and cdc25C phosphatase levels and to induce apoptosis in human prostate cancers (33). In the present study, quinalizarin was found to induce A549 cells arrest at $\mathrm{G}_{0} / \mathrm{G}_{1}$ phase, thus suggesting that quinalizarin may induce cell cycle arrest at different phases. CDK2/4/6 and cyclin D1/E are known to be involved in the regulation of $G_{0} / G_{1}$ phase. Because activation of the $\mathrm{CDK} /$ cyclin complex initiates entry into $G_{1}$ phase, the $G_{0} / G_{1}$ transition usually requires a functional CDK/cyclin complex (34). Our results indicated that quinalizarin induced $A 549$ cell cycle arrest at $G_{0} / G_{1}$ phase by suppressing CDK2/4/6 and cyclin D1/E and increasing p21 and $\mathrm{p} 27$ protein expression levels.

Apoptosis is a conserved programmed cell death mechanism that is involved in the elimination of cancer cells. Intrinsic apoptosis is also known as mitochondrial apoptosis because it depends on factors released from the mitochondria. The mitochondrial pathway is regulated by Bcl-2 family members, which include pro-apoptotic Bad and anti-apoptotic Bcl-2 proteins (35). Caspase-3 is a critical enzyme in apoptosis that cleaves several essential cellular proteins such as PARP (36). Many anti-cancer agents induce the intrinsic apoptotic pathway, which is characterized by increasing activation of caspase-3 and cleavage of PARP. Our present study showed that quinalizarin markedly induced the apoptosis of A549 cells by up-regulating Bad, down-regulating the expression of $\mathrm{Bcl}-2$ and activating caspase- 3 and PARP. These findings suggested that quinalizarin may induce mitochondrial-dependent apoptosis, regulate Bcl-2 and Bad expressions, and activate the mitochondrial cascade in lung cancer cells.

Furthermore, the underlying molecular mechanisms of quinalizarin-induced apoptosis indicated that quinalizarin induces cell apoptosis via suppression of the Akt, MAPK, STAT3 and p53 signalling pathways. The Akt signalling pathway is closely associated with CK2 and plays important roles in cell survival and apoptosis (37). The MAPK signalling pathways can be divided into three major subgroups, correlated with apoptosis: the ERK, JNK and p38 pathways (14). ERK is involved in the regulation of cell proliferation, differentiation and apoptosis in cancer cells (15). JNK is activated by environmental and toxic stresses and is important in inflammation through the control of cell proliferation, differentiation, survival and migration of various cell types (16). p38 is activated by cell stress-induced signalling in response to various factors including toxic chemicals and oxidative stress (17). STAT3 activation also leads to increased cell proliferation, angiogenesis, multidrug resistance and decreased cell apoptosis (18). p53 activates target genes involved in cell cycle arrest, apoptosis, senescence, anti-angiogenesis and autophagy, thereby suppressing malignant tumour transformation and preserving genomic integrity (38). Our results revealed that quinalizarin induces apoptosis by regulating the expression levels of proteins involved in the Akt, MAPK, STAT3 and p53 signalling pathways.
ROS are a group of highly reactive molecular oxygens continuously produced during mitochondrial respiration. ROS are usually maintained at tolerable levels under physiological conditions, whereas high levels of ROS are an important mechanism of cell death (39). Intracellular ROS levels have been reported to activate the MAPK signalling pathways (40). Imbalances due to either increased ROS production or decreased ROS degradation may cause excessive ROS accumulation, thus damaging to cell structures and compromising cellular functions (41). Our study showed that NAC completely restored the apoptotic mechanism of A549 cells induced by quinalizarin. This finding suggested that ROS mediate cell apoptosis. The expression levels of proteins involved in the MAPK and STAT3 signalling pathways were detected and revealed to increase expression levels of ERK and STAT3 and decrease expression levels of JNK and p38 with a corresponding decrease in ROS levels. These results revealed that quinalizarin regulates the MAPK and STAT3 signalling pathways and is closely linked to ROS generation. To determine whether STAT3 was inactivated in response to quinalizarin-induced MAPK activation, the p38 inhibitor, JNK inhibitor or ERK inhibitor was used to investigation the interaction between MAPK and STAT3. The results showed that the reactivation of the p38 inhibitor, JNK inhibitor or ERK inhibitor by quinalizarin-inhibited the STAT3 signalling pathway, indicating that STAT3 was regulated by the MAPK signalling pathway.

The present study demonstrated that quinalizarin inhibits lung cancer A549 cell proliferation, $G_{0} / G_{1}$ phase cell cycle arrest and apoptosis by increasing ROS generation and the activation or inactivation of the Akt, MAPK, STAT3 and p53 signalling pathways. This study provides evidence that quinalizarin is a potential therapeutic agent for the treatment of lung cancer. In future research, the effects of quinalizarin in vivo should be evaluated.

\section{Acknowledgements}

The present study was funded by Program of Cultivation and Support Projects of Heilongjiang Bayi Agricultural University (XA2015-04), Nature Science Foundation of Heilongjiang Province of China (LC2015036) and the Research Project of Heilongjiang Bayi Agricultural University (XYB2013-24).

\section{References}

1. Siegel RL, Miller KD and Jemal A: Cancer statistics, 2016. CA Cancer J Clin 66: 7-30, 2016.

2. Ruan Y, Hu K and Chen H: Autophagy inhibition enhances isorhamnetin-induced mitochondria-dependent apoptosis in non-small cell lung cancer cells. Mol Med Rep 12: 5796-5806, 2015.

3. Zhao GF, Huang ZA, Du XK, Yang ML, Huang DD and Zhang S: Molecular docking studies of traditional chinese medicinal compounds against known protein targets to treat non-small cell lung carcinomas. Mol Med Rep 14: 1132-1138, 2016.

4. Chen W, Zheng R, Baade PD, Zhang S, Zeng H, Bray F, Jemal A, $\mathrm{Yu}$ XQ and He J: Cancer statistics in China, 2015. CA Cancer J Clin 66: 115-132, 2016.

5. Dai GH, Meng GM, Tong YL, Chen X, Ren ZM, Wang K and Yang F: Growth-inhibiting and apoptosis-inducing activities of Myricanol from the bark of Myrica rubra in human lung adenocarcinoma A549 cells. Phytomedicine 21: 1490-1496, 2014. 
6. Xu K, Liu B and Liu Y: Impact of Brachyury on epithelial-mesenchymal transitions and chemosensitivity in non-small cell lung cancer. Mol Med Rep 12: 995-1001, 2015.

7. Guo W, Xie L, Zhao L and Zhao Y: mRNA and microRNA expression profiles of radioresistant NCI-H520 non-small cell lung cancer cells. Mol Med Rep 12: 1857-1867, 2015.

8. Chen X, Yang Z, Sun R, Mo Z, Jin G, Wei F, Hu J, Guan W and Zhong N: Preparation of lung-targeting, emodin-loaded polylactic acid microspheres and their properties. Int J Mol Sci 15 6241-6251, 2014.

9. Li Y, Guo G, Song J, Cai Z, Yang J, Chen Z, Wang Y, Huang Y and Gao Q: B7-H3 promotes the migration and invasion of human bladder cancer cells via the PI3K/Akt/STAT3 signaling pathway. J Cancer 8: 816-824, 2017.

10. Hu S, Huang L, Meng L, Sun H, Zhang W and Xu Y: Isorhamnetin inhibits cell proliferation and induces apoptosis in breast cancer via Akt and mitogen-activated protein kinase kinase signaling pathways. Mol Med Rep 12: 6745-6751, 2015.

11. Zhang G, Wang C, Sun M, Li J, Wang B, Jin C, Hua P, Song G, Zhang Y, Nguyen LL, et al: Cinobufagin inhibits tumor growth by inducing intrinsic apoptosis through AKT signaling pathway in human nonsmall cell lung cancer cells. Oncotarget 7: 28935-28946, 2016.

12. Zhang D, Chen B, Zhou J, Zhou L, Li Q, Liu F, Chou KY, Tao L and Lu LM: Low concentrations of trichosanthin induce apoptosis and cell cycle arrest via c-Jun N-terminal protein kinase/mitogen-activated protein kinase activation. Mol Med Rep 11: 349-356, 2015.

13. Zheng Y, McFarland BC, Drygin D, Yu H, Bellis SL, Kim H, Bredel $\mathrm{M}$ and Benveniste EN: Targeting protein kinase CK2 suppresses prosurvival signaling pathways and growth of glioblastoma. Clin Cancer Res 19: 6484-6494, 2013.

14. Pan B, Zhong W, Deng Z, Lai C, Chu J, Jiao G, Liu J and Zhou Q: Inhibition of prostate cancer growth by solanine requires the suppression of cell cycle proteins and the activation of ROS/P38 signaling pathway. Cancer Med 5: 3214-3222, 2016.

15. Zhai H, Hu S, Liu T, Wang F, Wang X, Wu G, Zhang Y, Sui M, Liu $\mathrm{H}$ and Jiang L: Nitidine chloride inhibits proliferation and induces apoptosis in colorectal cancer cells by suppressing the ERK signaling pathway. Mol Med Rep 13: 2536-2542, 2016.

16. Park KR, Yun HM, Quang TH, Oh H, Lee DS, Auh QS and Kim EC: 4-Methoxydalbergione suppresses growth and induces apoptosis in human osteosarcoma cells in vitro and in vivo xenograft model through down-regulation of the JAK2/STAT3 pathway. Oncotarget 7: 6960-6971, 2016.

17. Tsai WC, Bai LY, Chen YJ, Chu PC, Hsu YW, Sargeant AM and Weng JR: OSU-A9 inhibits pancreatic cancer cell lines by modulating p38-JAK-STAT3 signaling. Oncotarget 8: 29233-29246, 2017.

18. Miao D and Zhang L: Leptin modulates the expression of catabolic genes in rat nucleus pulposus cells through the mitogen-activated protein kinase and Janus kinase 2/signal transducer and activator of transcription 3 pathways. Mol Med Rep 12: 1761-1768, 2015

19. Principe $M$, Borgoni S, Cascione M, Chattaragada MS Ferri-Borgogno S, Capello M, Bulfamante S, Chapelle J, Di Modugno F, Defilippi P, et al: Alpha-enolase (ENO1) controls alpha v/beta 3 integrin expression and regulates pancreatic cancer adhesion, invasion, and metastasis. J Hematol Oncol 10: $16,2017$.

20. Shi XY, Xiong LX, Xiao L, Meng C, Qi GY and Li WL: Downregulation of caveolin-1 upregulates the expression of growth factors and regulators in co-culture of fbroblasts with cancer cells. Mol Med Rep 13: 744-752, 2016.

21. Khan M, Khan M, Al-Marri AH, Al-Warthan A, Alkhathlan HZ, Siddiqui MR, Nayak VL, Kamal A and Adil SF: Apoptosis inducing ability of silver decorated highly reduced graphene oxide nanocomposites in A549 lung cancer. Int J Nanomedicine 11: 873-883, 2016

22. Chen Z, Teo AE and McCarty N: ROS induced CXCR4 signaling regulates mantle cell lymphoma (MCL) cell survival and drug resistance in the bone marrow microenvironment via autophagy. Clin Cancer Res 22: 187-199, 2016.

23. Zhang W, Zhang Q, Jiang Y, Li F and Xin H: Effects of ophiopogonin B on the proliferation and apoptosis of SGC-7901 human gastric cancer cells. Mol Med Rep 13: 4981-4986, 2016.
24. Chen Y, Liu JM, Xiong XX, Qiu XY, Pan F, Liu D, Lan SJ, Jin S, Yu SB and Chen XQ: Piperlongumine selectively kills hepatocellular carcinoma cells and preferentially inhibits their invasion via ROS-ER-MAPKs-CHOP. Oncotarget 6: 6406-6421, 2015.

25. Cozza G, Mazzorana M, Papinutto E, Bain J,Elliott M, di Maira G, Gianoncelli A, Pagano MA, Sarno S, Ruzzene M, et al: Quinalizarin as a potent, selective and cell-permeable inhibitor of protein kinase CK2. Biochem J 421: 387-395, 2009.

26. Song C, Gowda C, Pan X, Ding Y, Tong Y, Tan BH, Wang H, Muthusami S, Ge Z, Sachdev M, et al: Targeting casein kinase II restores Ikaros tumor suppressor activity and demonstrates therapeutic efficacy in high-risk leukemia. Blood 126: 1813-1822, 2015.

27. Hung MS, Xu Z, Chen Y, Smith E, Mao JH, Hsieh D, Lin YC, Yang CT, Jablons DM and You L: Hematein, a casein kinase II inhibitor, inhibits lung cancer tumor growth in a murine xenograft model. Int J Oncol 43: 1517-1522, 2013.

28. Zhou Y, Li K, Zhang S, Li Q, Li Z, Zhou F, Dong X, Liu L, Wu G and Meng R: Quinalizarin, a specific CK2 inhibitor, reduces cell viability and suppresses migration and accelerates apoptosis in different human lung cancer cell lines. Indian J Cancer 2 (Suppl 52): e119-e124, 2015.

29. Kim J, Choi WJ, Moon SH, Jung J, Park JK, Kim SH and Lee JO: Micropillar arrays as potential drug screens: Inhibition of micropillar-mediated activation of the FAK-Src-paxillin signaling pathway by the CK2 inhibitor CX-4945. Acta Biomater 27: 13-20, 2015

30. Kang NH, Shin HC, Oh S, Lee KH, Lee YB and Choi KC: Soy milk digestion extract inhibits progression of prostate cancer cell growth via regulation of prostate cancer-specific antigen and cell cycle-regulatory genes in human LNCaP cancer cells. Mol Med Rep 14: 1809-1816, 2016.

31. Liu L, Wang D, Li L, Ding X and Ma H: Dehydroepiandrosterone inhibits cell proliferation and improves viability by regulating $\mathrm{S}$ phase and mitochondrial permeability in primary rat Leydig cells. Mol Med Rep 14: 705-714, 2016

32. Chen L, Tian H, Li M, Ge C, Zhao F, Zhang L, Li H, Liu J, Wang T, Yao M and Li J: Derivate isocorydine inhibits cell proliferation in hepatocellular carcinoma cell lines by inducing G2/M cell cycle arrest and apoptosis. Tumour Biol 37: 5951-5961, 2016.

33. Schneider CC, Götz C, Hessenauer A, Günther J, Kartarius S and Montenarh M: Down-regulation of CK2 activity results in a decrease in the level of cdc25C phosphatase in different prostate cancer cell lines. Mol Cell Biochem 356: 177-184, 2011.

34. Shi W, Deng J, Tong R, Yang Y, He X, Lv J, Wang H, Deng S, Qi P, Zhang D and Wang Y: Molecular mechanisms underlying mangiferin-induced apoptosis and cell cycle arrest in A549 human lung carcinoma cells. Mol Med Rep 13: 3423-3432, 2016.

35. Woo SM, Choi YK, Kim AJ, Cho SG and Ko SG: p53 causes butein-mediated apoptosis of chronic myeloid leukemia cells. Mol Med Rep 13: 1091-1096, 2016.

36. Wu Y, Chen Y, Wu Q, Jia L and Du X: Minocycline inhibits PARP-1 expression and decreases apoptosis in diabetic retinopathy. Mol Med Rep 12: 4887-4894, 2015.

37. Zeng J, Chen S, Li N, Chen L, Su J, Niu G, Zhu S and Liang Y: Sasanquasaponin from Camellia oleifera Abel. induces apoptosis via Bcl-2, Bax and caspase-3 activation in HepG2 cells. Mol Med Rep 12: 1997-2002, 2015.

38. Jin J, Lin G, Huang H, Xu D, Yu H, Ma X, Zhu L, Ma D and Jiang H: Capsaicin mediates cell cycle arrest and apoptosis in human colon cancer cells via stabilizing and activating p53. Int J Biol Sci 10: 285-295, 2014.

39. Conway GE, Casey A, Milosavljevic V, Liu Y, Howe O, Cullen PJ and Curtin JF: Non-thermal atmospheric plasma induces ROS-independent cell death in U373MG glioma cells and augments the cytotoxicity of temozolomide. Br J Cancer 114: 435-443, 2016.

40. Zhao W, Lu M and Zhang Q: Chloride intracellular channel 1 regulates migration and invasion in gastric cancer by triggering the ROS-mediated p38 MAPK signaling pathway. Mol Med Rep 12: 8041-8047, 2015.

41. Aredia F, Czaplinski S, Fulda S and Scovassi AI: Molecular features of the cytotoxicity of an NHE inhibitor: Evidence of mitochondrial alterations, ROS overproduction and DNA damage. BMC Cancer 16: 851, 2016 